\title{
Power Quality Measurement and Analysis in Electric Arc Furnace for Turkish Electricity Transmission System
}

\author{
Mustafa Seker $^{1}$, Arif Memmedov ${ }^{2}$, Rafael Huseyinov ${ }^{1}$, Serdar Kockanat ${ }^{1}$ \\ ${ }^{I}$ Department of Electrical and Electronics Engineering, Faculty of Engineering, \\ Cumhuriyet University, \\ 58140, Sivas, Turkey \\ ${ }^{2}$ Department of Electrical and Electronics Engineering, Faculty of Engineering, \\ Inonu University, \\ 44280, Malatya, Turkey \\ mustafaseker@cumhuriyet.edu.tr
}

\begin{abstract}
During the recent years, with its increasing steel production, Turkey has succeeded to become one of the ten biggest steel producer countries in the world. In Turkey, there are 3 integrated plants and 27 Electric Arc Furnace (EAF) plants in operation for iron-steel production. $71,3 \%$ of the steel products was produced by EAF plants and also it is planned for new plants to produce with are furnaces. In this study, power quality problems caused by 60MVA arc furnace at Sivas Iron and Steel Incorporated Company (SIDEMIR), have been examined by HIOKI 3197 and Chauvin $\operatorname{Arnoux}(\mathrm{CA})$ 8332B power quality analysers according to IEC 61000-4-30 standards. In addition, with equivalent circuit model designed by utilizing Electromagnetic Transient Program(EMTP) software, possible harmonic effects on the electricity grid have been evalauted and by determining power quality problems caused by EAF-60 furnace, solution offers were presented in order to improve power quality.
\end{abstract}

Index Terms-Electric arc furnace; power quality; flicker; harmonics.

\section{INTRODUCTION}

The iron and steel industry has an important role in global economy and meets the raw material requirements of many sectors especially such as automotive and construction. During the recent years Turkey, with its increasing steel production, has succeeded to become one of the ten biggest steel producer countries in the world. Today in Turkey, $71,3 \%$ of the steel product is produced by Electric Arc Furnace (EAF) plants [1] and the total electricity requirement of these plants is approximately one-tenth of production demand power in Turkey [2].

Developments in EAF field have started after the Second World War and showed a fast progression in parallel with the technological developments in Electricity, Metallurgy and Mechanic fields. EAFs with low melting capacities have become popular among other systems by their improving melting capacity and lower production costs. Today with

Manuscript received 24 April, 2017; accepted 11 October, 2017.

This work was supported by Inonu University Scientific Research Projects Department (Ï̈BAP). Project number: FDK-2011-135. increasing demand of metal the melting capacities of EAFs have become necessary to increase. Therefore; in order to increase EAF capacities, transformer power as well as the energy used have been increasing [3]. Requirement of some new technologies has come out in parallel with increasing EAF capacities. Therefore, it is necessary to use cooling systems in furnace linings [4], $\mathrm{O}_{2}$ burners for fast melting [5], electrode checking with automatic control systems [6], 7] and computer systems to control other processes. Although EAFs have many advantages in iron-steel production, they cause power quality problems because of their nonlinear working characteristics [8]-[15].

Power quality problems caused by EAFs have been an investigation subject for many researchers. Issouribehere et al. have defined single-phase equivalent circuit of EAF plants considering different working conditions of EAFs at boring, melting and refining processes [16]. In addition, Issouribehere et al. have examined the relations between the regulations of EAF in Argentina and limit values at power quality [17]. Mayardomo et al., in their studies, have determined EAF plant power quality problems according to the IEC 61000-4-30 standard [18]. Mayardomo and Hernandez, in addition to their studies, have examined EAF based interharmonics and described flicker propagation based on interharmonics. Deacanu et al., have performed experimental analyses and modelling for modernization of 100-t EAF system [19]. Donsion, using experimental measurements and analyses, has examined the effect of Static Var Compensation (SVC) systems on harmonics, flicker and imbalance caused by EAFs [20]. Boulet et al., in their studies, have searched for the effect of accuracy of EAF power quality measurements and they have determined that $2 \%$ faulty measurements were carried out when filter groups were not used during measurement [21]. As for studies in Turkey, in scope of Power Quality National Project, power quality problems on the national network are continuously monitored by remote monitoring systems and it is determined that $2^{\text {nd }}$ harmonic values are increased because of using SVC systems on EAFs[22], [23]. 
In this study, power quality problems caused by 60MVA arc furnace at Sivas Iron and Steel Incorporated Company (SIDEMIR) are examined by HIOKI 3197 and Chauvin Arnoux(CA) 8332B power quality analysers according to the IEC 61000-4-30 standard [24]. Also with equivalent circuit model, designed by utilizing Electromagnetic Transient Program (EMTP) software, possible harmonic effects on the electricity network have been considered and solution offers are presented in order to improve power quality of the existing plant. Thus, the results of this study have great importance in terms of planning new EAFs to be built in Turkey and reducing power quality problems.

\section{BASIC ACCEPTANCES OF POWER QUALITY PARAMETERS ON ELECTRICAL SYSTEMS}

According to basic acceptances of power quality, current and voltage have non-sinusoidal structures and are stated with (1) and (2):

$$
\begin{aligned}
& u(t)=\sum_{k=1}^{N} U k \cdot \sqrt{2} \cdot \sin (k \omega t+\gamma k), \\
& i(t)=\sum_{k=1}^{N} I k \cdot \sqrt{2} \cdot \sin (k \omega t+\gamma k-\theta k) .
\end{aligned}
$$

Total harmonic distortion of current and voltage is defined in relation with RMS values of current and voltage at basic frequency [25]:

- total harmonic distortion of voltage value

$$
T H D U=\sqrt{\sum_{n=2}^{N}\left(\frac{U_{n}}{U(1)}\right)^{2}},
$$

- total harmonic distortion of current value

$$
T H D I=\sqrt{\sum_{n=2}^{N}\left(\frac{I_{n}}{I_{(1)}}\right)^{2}},
$$

are defined with the above equations. In these equations, $U_{(I)}$ and $I_{(l)}$ are the RMS values of current and voltage at basic frequency.

Some researchers have stated flicker effect and harmonics to be in direct relation with each other [26], [27]. Flicker effect is fluctuations that are observed at voltage amplitude and that can be perceived by the eye at about $3 \mathrm{~Hz}-10 \mathrm{~Hz}$. Flicker effect can be modelled by amplitude modulation according to the IEC 61000-4-15 standard in international literature [28]. According to this definition flicker modulation can be expressed with (5)

$$
P s t=(A+m \cdot \cos (\omega t+\varphi)) \cdot \sin (\omega c . t),
$$

where $m$ is modulation index of flicker statement, $\omega_{c}$ is frequency of the power system and $\mathrm{A}$ is modulation amplitude. Also, according to the IEC 61000-4-15 standard, two different flicker effects are defined as short-term flicker magnitude $\left(P_{s t}\right)$ and long term flicker magnitude $\left(P_{l t}\right)$. Short term flicker magnitude can be calculated according to 10 minutes of measuring period as in (6)

$$
P_{s t}=\sqrt{\begin{array}{l}
0,0314 \cdot P_{0,1}+0,0525 \cdot P_{1 S}+0,0657 \cdot P_{3 S}+ \\
+0,28 \cdot P_{10 S}+0,08 P_{50 S}
\end{array}} .
$$

In this equation $P_{0.1}, P_{1 s}, P_{3 s}, P_{10 s}, P_{50 s}$ are the flicker levels reached for the $50 \%, 10 \%, 3 \%, 1 \%, 0,1 \%$ values of time during the measurement period. $P_{0,1}, P_{1 s}, P_{3 s}, P_{10 s}, P_{50 s}$ values can be calculated according to assumptions presented at [29].

Long term flicker effect is expressed in (7) related to short term values in a longer time period

$$
P l t=\sqrt[3]{\frac{\sum_{i=1}^{N}\left(P_{s t}(i)\right)^{3}}{N}},
$$

where $P_{s t}(i)(\mathrm{i}=1,2,3 \ldots)$ are successive $P_{s t}$ values and $N$ is the number of measurement period [29].

The magnitude of the flicker caused EAF loads can be obtained directly by measuring devices and also can be calculated from the voltage fluctuations that are measured by using advanced simulation programs. In order to prevent flicker effect problem EAFs should be connected at points with least voltage drop on the network. In the studies, it is determined that this voltage drop value should not exceed $2 \%$ at $132 \mathrm{kV}$ and lower voltage levels and $1.6 \%$ at voltage levels higher than $132 \mathrm{kV}$ [28].

\section{EXPERIMENTAL MEASUREMENT OF THE EAF-60 POWER QUALITY PARAMETERS}

Single line diagram of the dirty busbar feeding EAF-60 plant in SIDEMIR is given in Fig. 1.

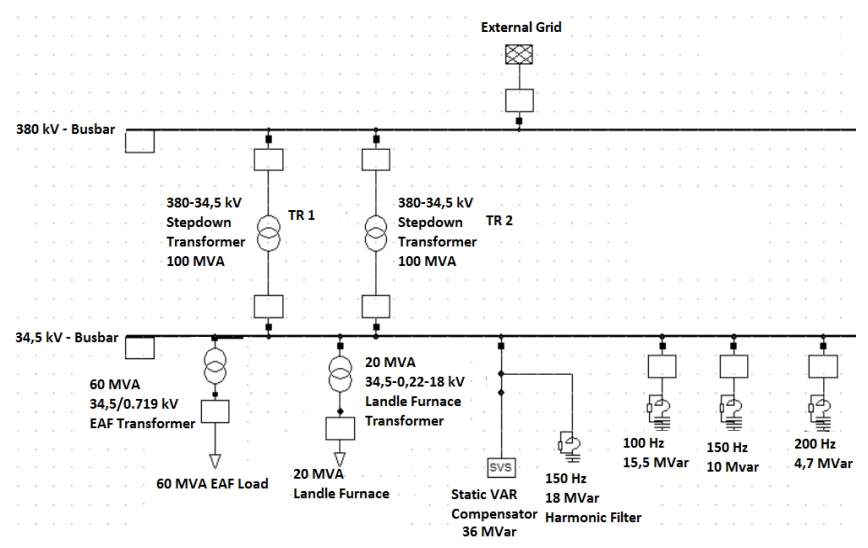

Fig. 1. Single Line Diagram of dirty busbar for SIDEMIR plant.

At the plant subject to examination, power quality problems caused by EAF-60 load have been recorded with the help of PQ analysers at various times, daily and weekly between the dates 28.04.2012-11.07.2012. Since the EAF load shows similar stochastic behaviour at the different melting periods, the measurement taken between dates 10.07.2012-11-07.2012 have been presented in this study in order to provide better understanding of the graphs, which are obtained experimentally.

Between the dates 10/07/2012-11/07/2012, Chauvin Arnoux (CA) 8332B power quality analyser was connected 
with three phase to the $34.5 \mathrm{kV}$ busbar of the circuit of which the single line figure was given and power quality problems on the $34.5 \mathrm{kV}$ busbar were recorded(as 3 seconds cycles and 20 seconds averages). Synchronously HIOKI 3197 power quality analyser was connected to the secondary measurement cell of the TR 1 transformer and current and voltage changes at different operational processes of the EAF were recorded with 12 cycles and $1024 \mathrm{~Hz}$ resolution.

\section{A. $34.5 \mathrm{kV}$ Busbar Measurement Results for EAF Plant}

Turkish Electricity Transmission Company (TEIAS) does not permit for connecting an analyser to $380 \mathrm{kV}$ main busbar. Because of that HIOKI 3197 power analyser has been connected to the secondary busbar of the Tr-1 transformer and assessments have been carried out by using transformation parameters of the transformer. CA 8332B power quality analyser has been connected to the $34.5 \mathrm{kV}$ busbar and power quality parameters have been measured according to four different operational status occurring at the melting process of the EAF as charging $(\mathrm{C})$, boring(B), melting(M) and refining(R) phases. Since plant execution does not allow for disabling compensation and filter groups during the measurement process the measurements have been taken when the compensation system and harmonic filters were on. In order to understand better the operational processes during the melting process of the EAF in subject the measurements during one melting process have been defined graphically and operational process times of the EAF load during one melting process are shown in Table I.

TABLE I. MEASURENT PHASE TIMES OF EAF-60 LOAD IN MELTING PROCESS.

\begin{tabular}{|c|c|c|c|c|c|c|c|c|c|}
\hline \multirow[b]{2}{*}{$\begin{array}{l}\text { Time } \\
(\mathrm{min})\end{array}$} & \multicolumn{9}{|c|}{ The Phases of the EAF in Melting Process } \\
\hline & 7 & 13 & 4 & 16 & 5 & 12 & 4 & 26 & 4 \\
\hline $\begin{array}{c}\text { Plant } \\
\text { melting } \\
\text { process }\end{array}$ & off & $\begin{array}{l}\mathrm{C}_{1} \\
\mathrm{~B} \\
\mathrm{M}\end{array}$ & off & $\begin{array}{c}\mathrm{C}_{2} \\
\mathrm{~B} \\
\mathrm{M}\end{array}$ & off & $\begin{array}{c}\mathrm{C}_{3} \\
\mathrm{~B} \\
\mathrm{M}\end{array}$ & off & $\begin{array}{c}\mathrm{C}_{4} \\
\mathrm{~B} \\
\mathrm{M} \\
\mathrm{R}\end{array}$ & off \\
\hline
\end{tabular}

As seen in Table $\mathrm{I}, \mathrm{C}_{(\mathrm{i})}, \mathrm{B}, \mathrm{M}$ and $\mathrm{R}$ are referred charge number, boring, melting and refining respectively for a melting process when SVC system status is on.

Active and reactive power changes caused by EAF load during the melting process in Table I are graphically shown in Fig. 2 and the energy values obtained in this measurement period are shown in Table II.

TABLE II. ENERGY VALUES IN A MELTING PROCESS OF 87 MINUTE.

\begin{tabular}{|c|c|c|c|c|}
\hline \multicolumn{5}{|c|}{ Energy Values in Melting Process } \\
\hline & $\begin{array}{c}\% \\
\text { Inductive } \\
\text { Reactive/ } \\
\text { Active }\end{array}$ & $\begin{array}{c}\text { Active } \\
\text { Energy } \\
\text { (MWh) }\end{array}$ & $\begin{array}{c}\text { Reactive } \\
\text { Energy } \\
\text { (Inductive) } \\
\text { (MVARh) }\end{array}$ & $\begin{array}{c}\text { Active } \\
\text { Power Max. } \\
\text { Value } \\
\text { (MW) }\end{array}$ \\
\hline $\begin{array}{c}\text { Primary Side } \\
\text { of EAF } \\
\text { Transformer }\end{array}$ & 78,44 & 40,194 & 31,529 & 52,834 \\
\hline
\end{tabular}

Inductive/Reactive ratio of the EAF load in subject is seen as $78.44 \%$. It means the inductive power factor is about 0.8 . The power factor of the "A" phase measured at the $34.5 \mathrm{kV}$ busbar is graphically shown in Fig. 3.

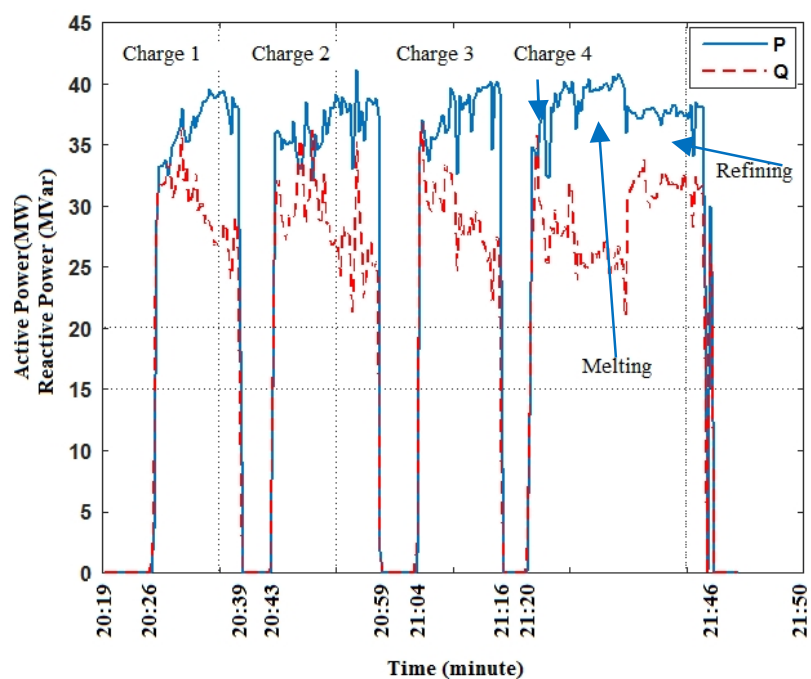

Fig. 2. Total Active (P) and Reactive Power (Q) changes of three phase measured by CA 8332B PQ Analyzer during a melting process of the 60 MVA EAF when SVC System and Harmonic Filters status are "on".

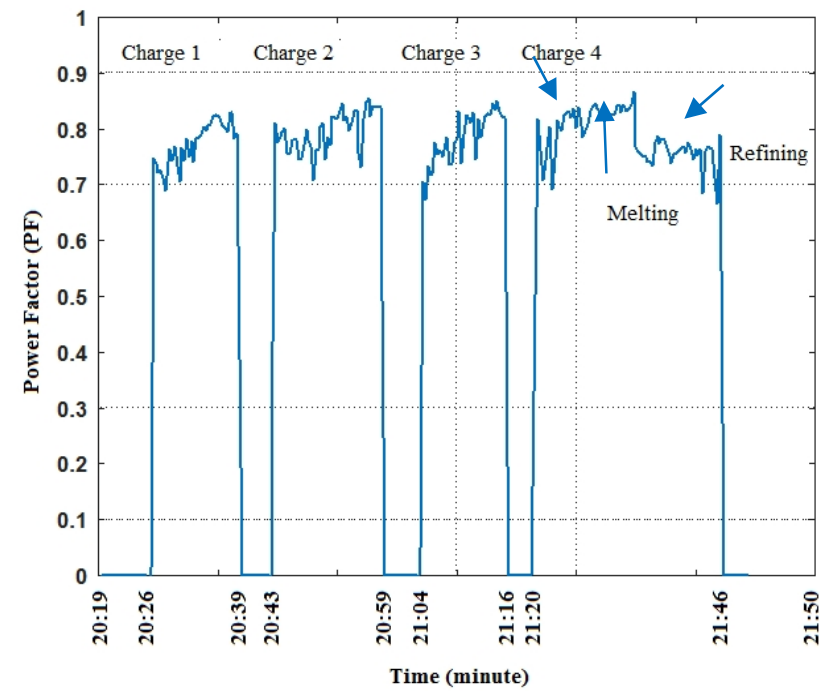

Fig. 3. Power Factor changes of the "A" phase measured by CA 8332B PQ Analyser during a melting process of the 60 MVA EAF when SVC System and Harmonic Filters status are "on".

As shown in Fig. 3, when reactive power compensation is realized by Static Var Compensation (SVC) the average power factor value comes out about 0.8 . This case shows that SVC system successfully provides reactive power compensation of the system.

\section{B. Measurement and Examination of Current and Voltage Harmonics caused by EAF-60}

$\mathrm{I}_{\mathrm{K}} / \mathrm{I}_{\mathrm{L}}$ value, expressed in the regulations of TEIAS, should be calculated in order to define the standards to be followed for determining harmonic current limit values on the electricity transmission system in Turkey and based on this value limit values for harmonic currents should be defined [30]. The short circuit current of the $380 \mathrm{kV}$ busbar feeding the EAF system is $11070 \mathrm{~A}$, so the short circuit current of the $34.5 \mathrm{kV}$ busbar can be calculated as follows:

$$
\left\{\begin{array}{l}
S_{\text {base }}=100 \mathrm{MVA}, \\
S=\sqrt{3} .380000 \text {.Ibase }, \\
I_{\text {base }}=144 \mathrm{~A}, \\
I=\text { Ipu.Ibase }=\frac{11070}{144}=76.875 \mathrm{~A} .
\end{array}\right.
$$


There are two transformers in the HV (high voltage) stepdown transformer station and Uk \% values are 14,8\%. Considering these acceptances, p.u values based on transformer power and $\mathrm{S}_{\text {base }}$ power:

$\mathrm{Uk}=14.8=\mathrm{X}_{\text {trA(p.u) }}=\mathrm{X}_{\text {trB(p.u). }}$

Transformer A and Transformer B impedances:

$\mathrm{X}_{\mathrm{s}(\mathrm{p} . \mathrm{u})}=1 / 76.875=0,0130$ (p.u).

Total impedances can be defined as

$$
\mathrm{X}_{\text {total }}=\mathrm{X}_{\mathrm{s}}+\mathrm{X}_{\mathrm{trA}} / / \mathrm{X}_{\mathrm{trB}}=0,0879 \text { (p.u). }
$$

On the $34.5 \mathrm{kV}$ busbar, short circuit current p.u value is $1 / 0.0879=11.376$ (p.u). Here $\mathrm{I}_{\text {base }}$ value:

$$
\left\{\begin{array}{l}
\text { Sbase }=\sqrt{3} . \text { Vbase.Ibase }, \\
100=\sqrt{3} \cdot 34500 . \text { Ibase } .
\end{array}\right.
$$

From here $I_{\text {base }}$ current is calculated as 1673 A. $I_{K}=$ $\mathrm{I}_{\text {base }} *(\mathrm{p} . \mathrm{u}$ value $)=1673 \times 11.376=19032 \mathrm{~A}$.

Having the ratio of $\mathrm{I}_{\mathrm{K}}\left(\mathrm{I}_{\mathrm{K}}\right.$ - short circuit current), calculated above, over $I_{L}$ value the $I_{K} / I_{L}$ ratio is calculated. $I_{L}$ value is calculated as $1023 \mathrm{~A}$ for plant main input and 1071 A for arc furnace input.

For dirty busbar input $I_{K} / I_{L}=17.7700 \mathrm{~A}$.

For arc furnace input $I_{K} / I_{L}=18.6041 \mathrm{~A}$.

Based on these calculated values, for current harmonic limits the values on the first column of the ccceptable current harmonic limits in the "Electricity Transmisson System Supply Safety and Quality Regulation" table are accepted [30]. Total harmonic distortion of the three phases measured by the CA $8332 \mathrm{~B}$ at the $34.5 \mathrm{kV}$ busbar is shown in Fig. 4 . Based on the limit values the total harmonic distortion values, measured in relation with each even and odd current harmonic, are also shown in Fig. 5.

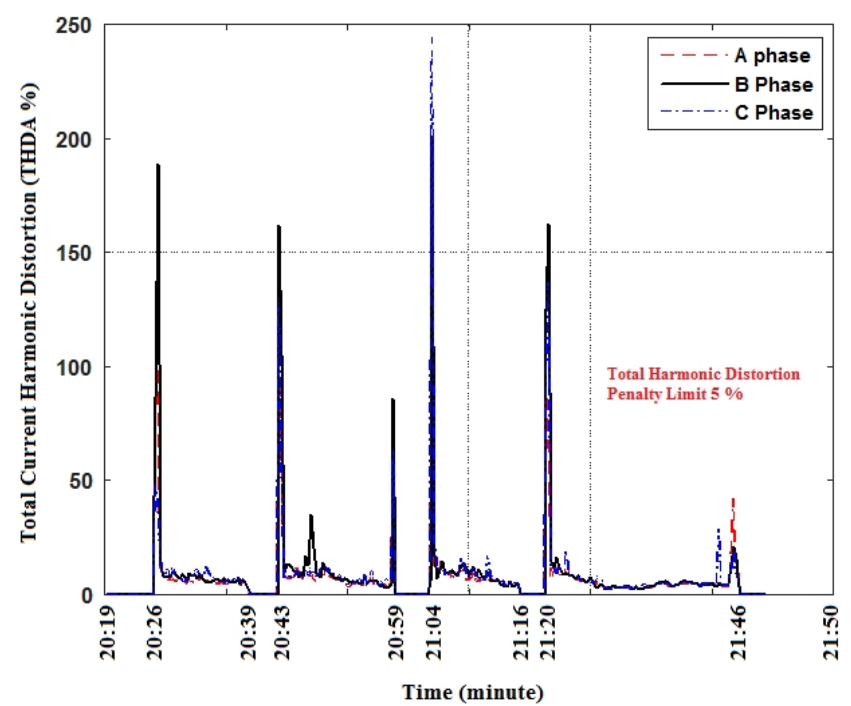

Fig. 4. Total Harmonic Distortion of the three phases measurement at the $34.5 \mathrm{kV}$ main busbar feeding the EAF-60(Harmonic distortion limit value is $5 \%$ ).

As it is seen in the measurement results, shown in Fig. 5, other current harmonic values except 21, 23, 24, 25, 27, 29, 30 and $31^{\text {th }}$ harmonics are determined to be higher than the standards defined in the regulation. Most of the current harmonic distortions that effect power quality occurs at the $2^{\text {nd }}, 3^{\text {rd }}, 4^{\text {th }}$ and $5^{\text {th }}$ harmonics and harmonic current root mean square (RMS) values of these current harmonics at boring, melting and refining phases are shown in Fig. 6.
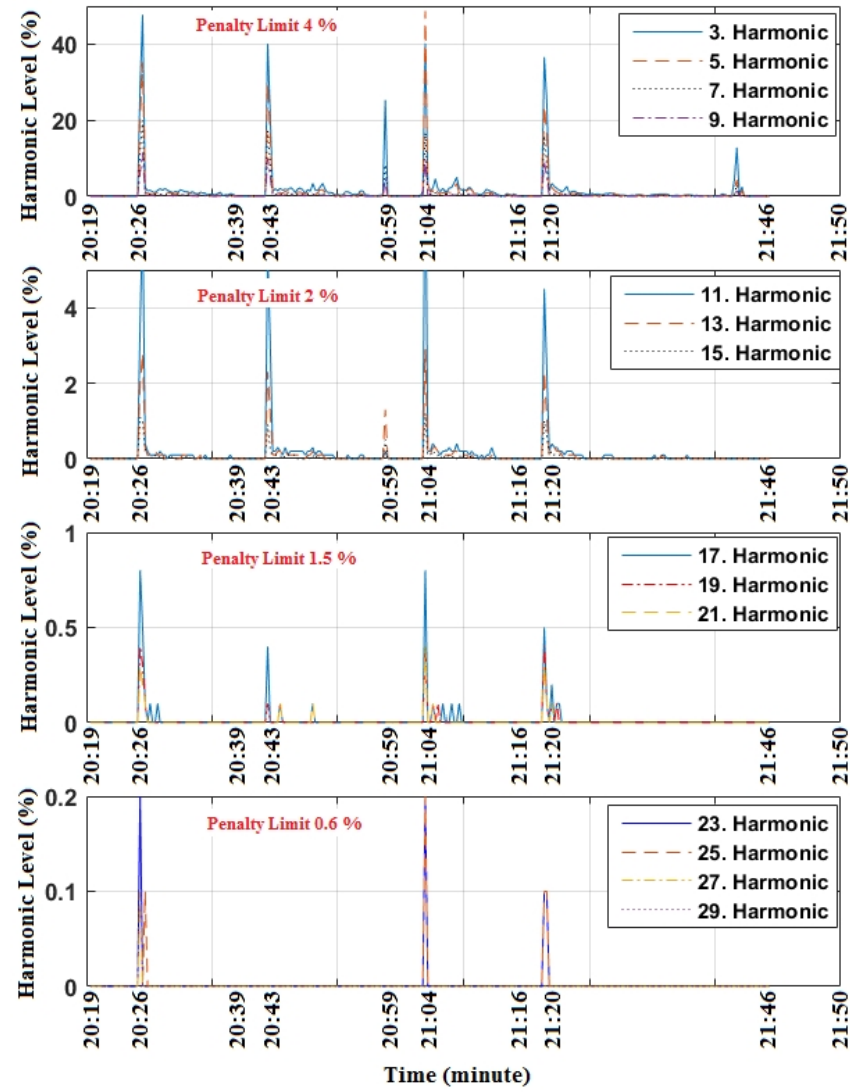

(a)
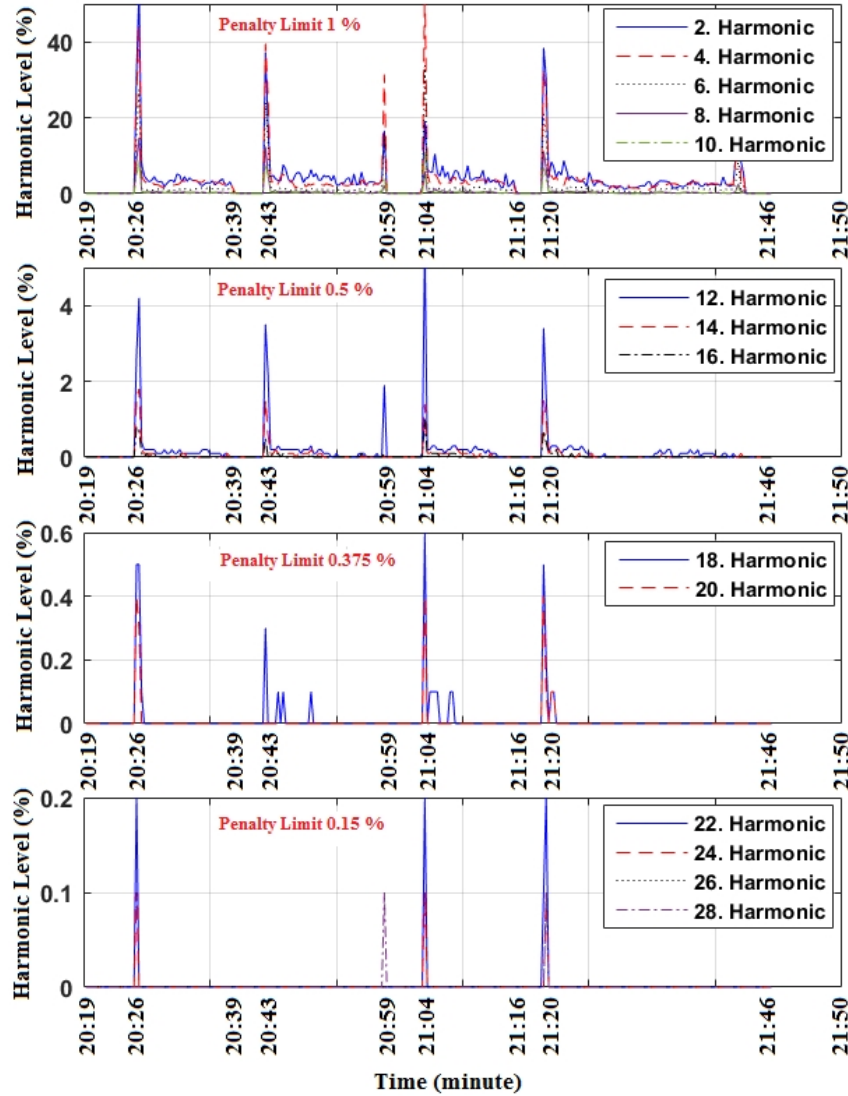

(b)

Fig. 5. Comparison of the limit with the current harmonics of " $A$ " phase at the $34.5 \mathrm{kV}$ main busbar feeding the EAF-60. a) odd harmonics, b) even harmonics. 


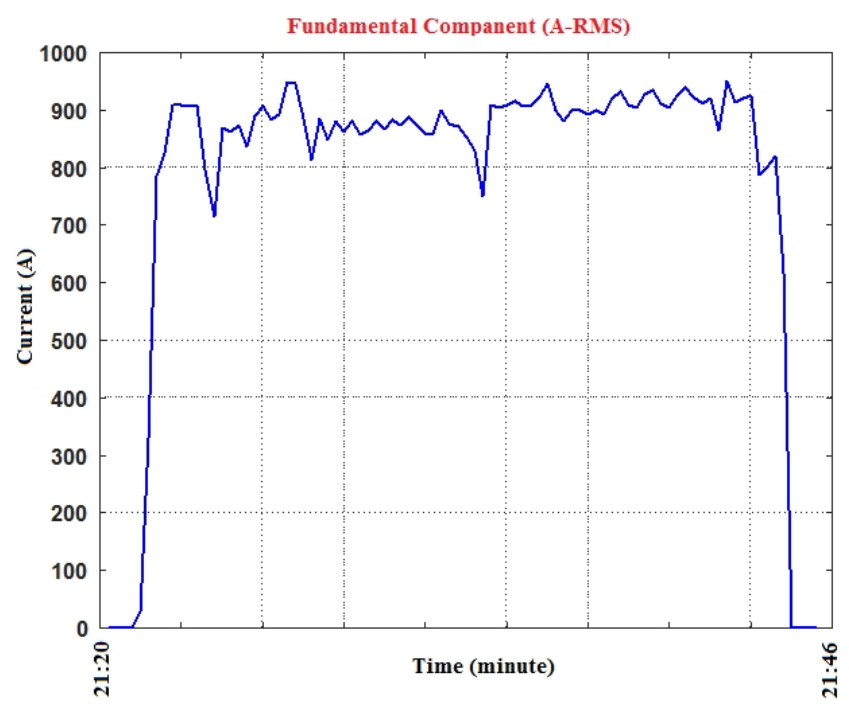

(a)

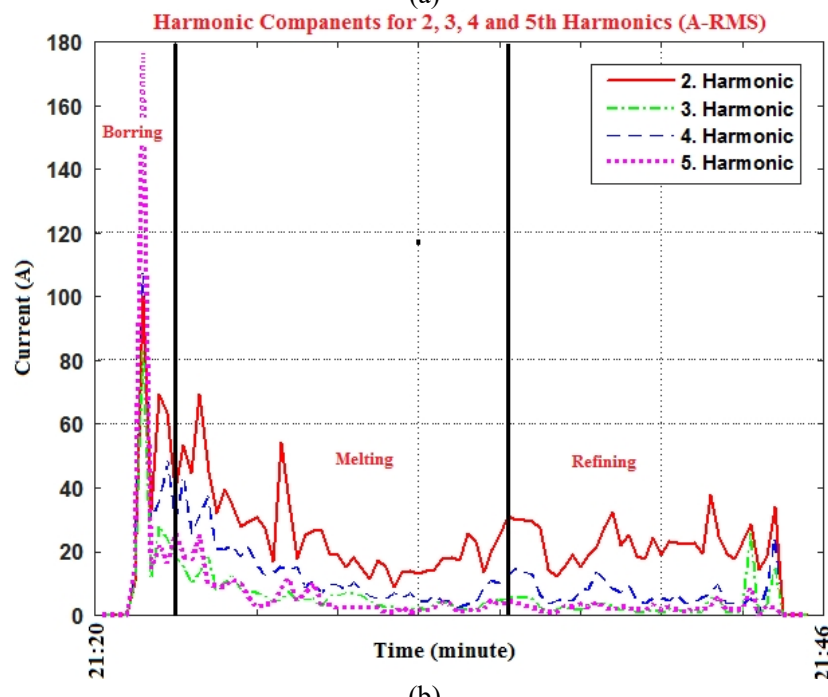

(b)

Fig. 6. Basic current harmonic at boring, melting and refining processes in a melting process in primer side (a), changes of the RMS values of the 2 , 3,4 and $5^{\text {th }}$ Harmonic currents in primer side (20seconds average values obtained by 10 -cycles averages are graphically shown) (b).

As depicted in Fig. 6, it is seen that harmonic currents in EAF operational process occur more in boring process and less changes of harmonic currents are in refining process.

When voltage harmonics of the $34.5 \mathrm{kV}$ busbar feeding the EAF system are examined; it is seen that other voltage harmonic values except $2^{\text {nd }}, 3^{\text {rd }}, 4^{\text {th }}$ and $6^{\text {th }}$ harmonics are in desired limit values stated in the regulations. While the $2^{\text {nd }}$ and $4 \mathrm{t}^{\text {th }}$ harmonic limit values are generally higher than the standards $3^{\text {rd }}$ and $6^{\text {th }}$ harmonics occasionally exceed the limit value. In order to understand voltage harmonics better, percental changes of $2-7^{\text {th }}$ voltage harmonics (of about 10 hours) by time are shown in Fig. 7 and percental change of the total voltage harmonic distortion by time is shown in Fig. 8.

\section{Examination of Flicker Effect Caused by EAF-60}

It is stated that the ratio of the minimum short circuit power to the nominal furnace power at the common connection point where EAFs are supplied should be more than 80 to eliminate flicker effect [31]. Contrarily Mendis et al. have stated that this ratio should be more than 50 [32]. The acceptance of (11) can be used between the short circuit power at the common connection point and the arc furnace power.
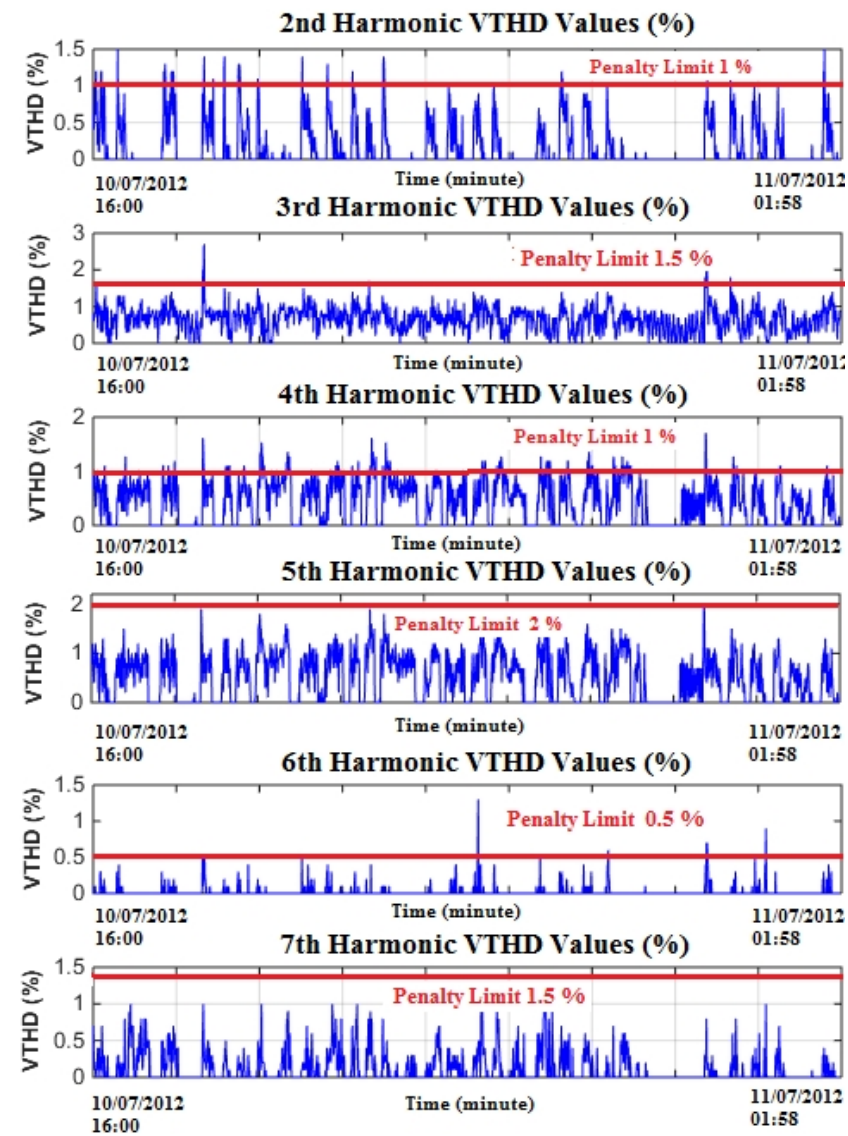

Fig. 7. Comparison of the limit values with the voltage harmonics of the "A" $\mathrm{kV}$ main busbar feeding, for about 10 hours of measurement period.

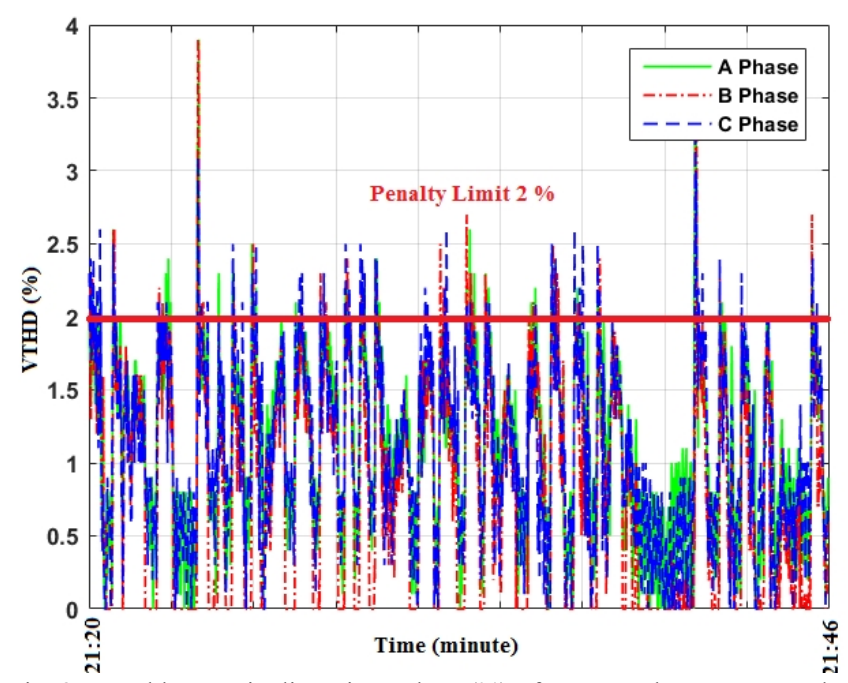

Fig. 8. Total harmonic distortion values (\%) of $\mathrm{A}, \mathrm{B}, \mathrm{C}$ phases measured at $34.5 \mathrm{kV}$ main busbar by the CA $8332 \mathrm{PQ}$ analyzer in about 10 hours of measurement period.

$$
\text { Max.MeltingPower } \leq \frac{1}{80 \cdot \sqrt[4]{n}} S_{k}
$$

where $\mathrm{S}_{\mathrm{k}}$ is network short circuit power at the common connection point and $\mathrm{n}$ is the number of furnaces operating together. In developed countries average short circuit powers in $380 \mathrm{kV}$ systems are above 16000 MVA while the minimum short circuit power $\left(\mathrm{SCMVA}_{\min }\right)$ of the network connection point of the EAF in subject is $7250 \mathrm{MVA}$ and there is no other furnace connected on the network. In this 
case as the nominal power of the EAF is $60 \mathrm{MVA}$

$$
\frac{S C M V A_{M N}}{M V A_{E A F}}=\frac{7250}{60}=120.83,
$$

comes out. In this case flicker effect caused by EAFs can be expected to be less. Short term flicker magnitude (Pst) values, measured at the $34.5 \mathrm{kV}$ busbar feeding the EAF in a melting process (approximately 87 minutes), are shown in Fig. 9. Since long term flicker magnitude has been evaluated with periods of 2 hours the (Plt) values obtained between the dates $05 / 07 / 2012-07 / 07 / 2012$ in periods about 36 hours are shown in Fig. 10.

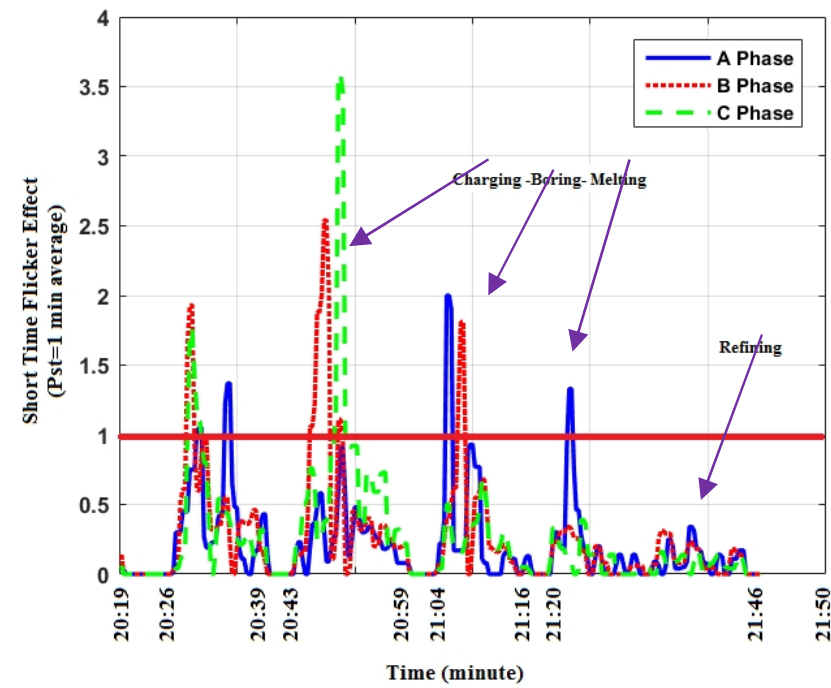

Fig. 9. Changes of short term flicker effect (Pst) at the $34.5 \mathrm{kV}$ busbar feeding of EAF plant (Penalty Limit, $\mathrm{P}_{\mathrm{st}}=1$ ).

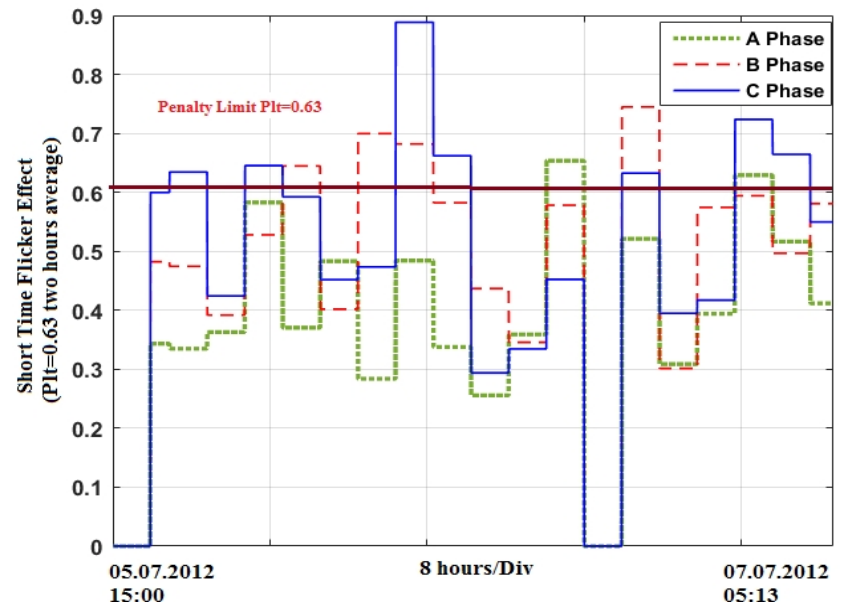

Fig. 10. Changes of long term flicker effect magnitude $\left(\mathrm{P}_{\mathrm{lt}}\right)$ measured at the $34.5 \mathrm{kV}$ busbar between the dates 05/07/2012-07/07/2012 and with 2 hours averages in 36 hours measurement period for EAF plant. (red; A phase, blue; B phase, black; C phase).

As it is seen in the measurement results although the ratio of the short circuit power at the common connection point to the short circuit power of the 60 MVA EAF is more than 80-100 flicker effect is observed.

\section{Current and Voltage Fluctuations at $34.5 \mathrm{kV}$ Busbar}

12-cycle waveforms and frequency spectrums(obtained by HIOKI 3197 PQ analyser) of the EAF TR1 transformer's $34.5 \mathrm{kV}$ secondary output during boring, melting and refining processes and theirs FFT analysis are respectively shown in Fig. 11, Fig. 12 and Fig. 13 as example.
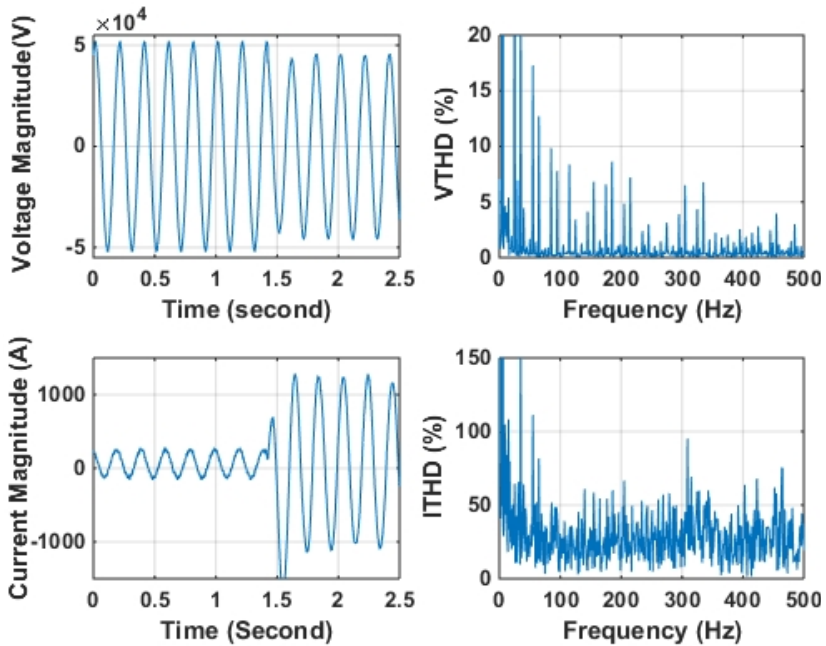

Fig. 11. Examination of the current and voltage fluctuations at the $34.5 \mathrm{kV}$ busbar during charge and boring process by FFT (SVC System and Harmonic Filters status are "on").
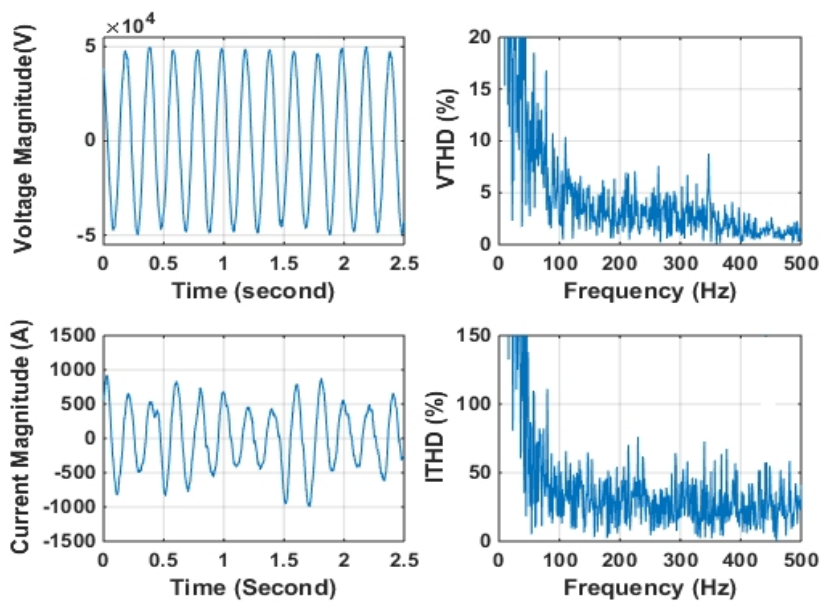

Fig. 12. Examination of the current and voltage fluctuations at the $34.5 \mathrm{kV}$ busbar during melting process by FFT (SVC System and Harmonic Filters status are "on").
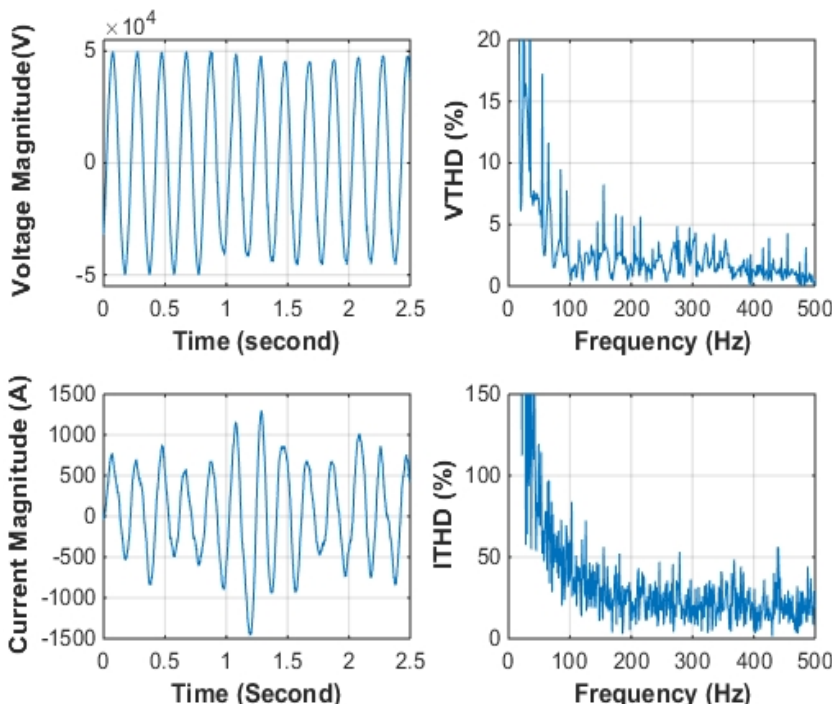

Fig. 13. Examination of the current and voltage fluctuations at the $34.5 \mathrm{kV}$ busbar during refining process by FFT.

As it is seen on the figures the most harmonic effect occurs during boring process and melting process. In refining process the current and the voltage fluctuations are almost in sinusoidal form. 


\section{E. Assessment of the Measurement Results}

When the measurement results are examined it is seen that at the EAF $34.5 \mathrm{kV}$ busbar the harmonic currents except 21, $23,24,25,27,29$ and $30^{\text {th }}$ harmonics exceed the limit values. $2^{\text {nd }}$ and $4^{\text {th }}$ voltage harmonics are above the limit values $3^{\text {rd }}$ and $6^{\text {th }}$ voltage harmonics occasionally exceed the limit values. Total harmonic distortion values of the current and the voltage harmonics exceed the limit values. The system is $78 \%$ inductive in terms of energy. Also, the short term and the long term flicker values are above the limit values and flicker effect can occur even the ratio of the short circuit power at the common connection point to EAF transformer power is above 100 .

\section{SOLUTION OFFERS TO IMPROVE POWER QUALITY IN SIDEMIR PLANT}

Electromagmetic Transient Program (EMTP) has been used to assess the effects of the harmonics at the $34.5 \mathrm{kV}$ medium voltage busbar in SIDEMIR plant. Calculation methods expressed in [33], [34] and circuit parameters have been used to define a phase equivalent circuit of the system feeding the EAF. $100 \mathrm{~Hz} 15.5 \mathrm{MVar}$ (C-Type), $150 \mathrm{~Hz}$ 10 MVar (C-Type) and $200 \mathrm{~Hz} 4.7$ MVar (Single Tuned) harmonic filters have been designed with the Static Var Compensation system shown in Fig. 1 and EMTP model used in analysis is shown in Fig. 14.

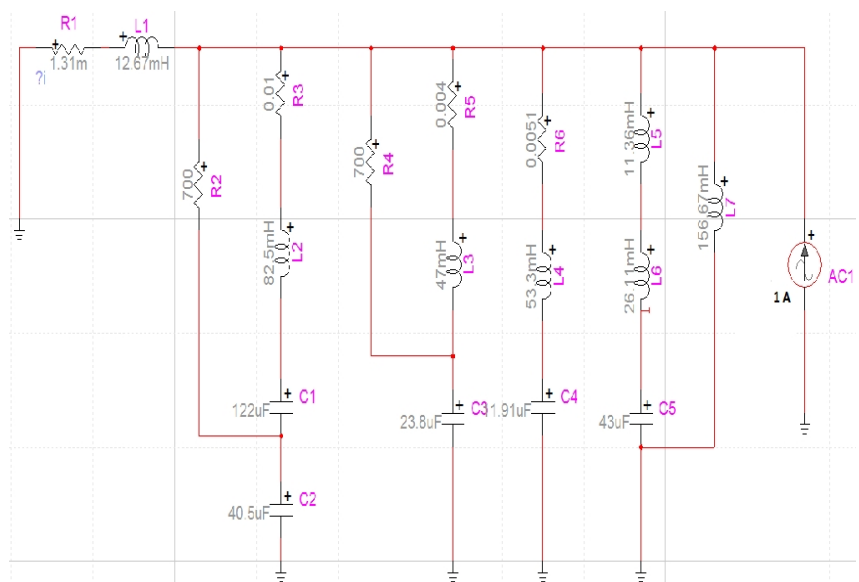

Fig. 14. The circuit scheme created by EMTP program used for harmonic analysis.

Using these scheme harmonics created at the network for 1A current has been calculated. As shown in Fig. 15 some currents are rising while some of them are filtered.

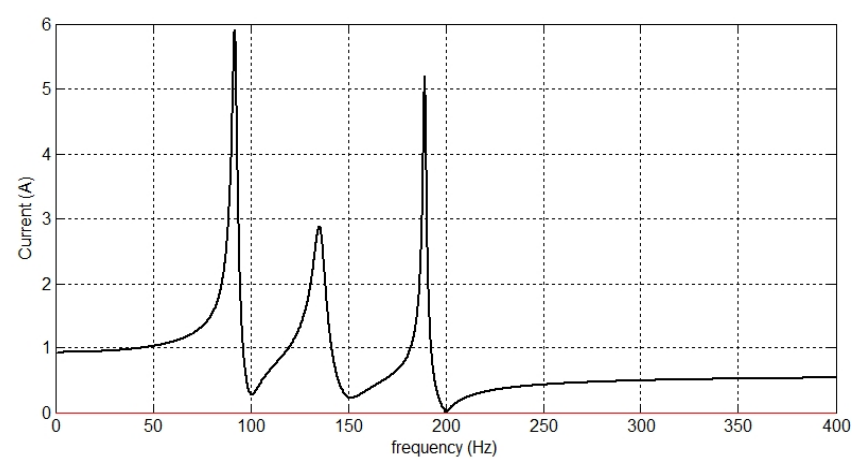

Fig. 15. Harmonic emission at the grid side of the SIDEMIR $34.5 \mathrm{kV}$ dirty busbar system.
However the $2^{\text {nd }}$ and $4^{\text {th }}$ harmonic currents are not filtered. This result corresponds to the experimental measurement scenarios. Also, it is determined that there is a little rise of the interharmonics between $100 \mathrm{~Hz}-150 \mathrm{~Hz}$.

As it is shown in the simulation result, the distortions of the $5^{\text {th }}$ and above harmonics will be caused by SIDEMIR plant. The filters are enough for the odd harmonics of the system.

The reason why the total harmonic distortion is over the limit values is the even harmonics. Also, the flicker effect is caused by the even harmonics. Reducing the even harmonics will provide improvement on both the total harmonic distortion and the flicker effect. Even harmonic currents are caused by the SVC system and the below methods can be offered to be able to reduce even harmonics.

\section{A. Reducing Even Harmonics}

It is determined out of the experimental and EMTP simulation results that even harmonics have not been filtered enough. The biggest effect is caused by the $2^{\text {nd }}$ harmonic component among the even harmonics. By changing the characterization of the $2^{\text {nd }}$ harmonic filter, the harmonic values can be reduced but this may cause the interharmonics between $50 \mathrm{~Hz}-100 \mathrm{~Hz}$ to rise. Reducing the furnace power can be considered as another method for reducing the even harmonics but this case will cause production losses.

\section{B. Increasing the Short Circuit Power of the Grid}

EAFs should be connected to the points with higher short circuit power on the grid and the effects of the currents caused by harmonics will reduce on the networks with high short circuit power. However, in the existing system, increasing the short circuit power of the network is under the initiative of TEIAS and it comes with a high cost.

\section{Reducing the Current of the Arc Furnace}

The current can be limited using series reactor in the EAF. But this case causes two negative effects. The first effect is the dropping production capacity because of the EAF current limitation and this is not a desired case. The second effect is the change of the harmonic currents created at the network when series reactor is used. When the simulation shown in Fig. 19, it is repeated with series reactor application the frequency-current change occurs as shown in Fig. 16.

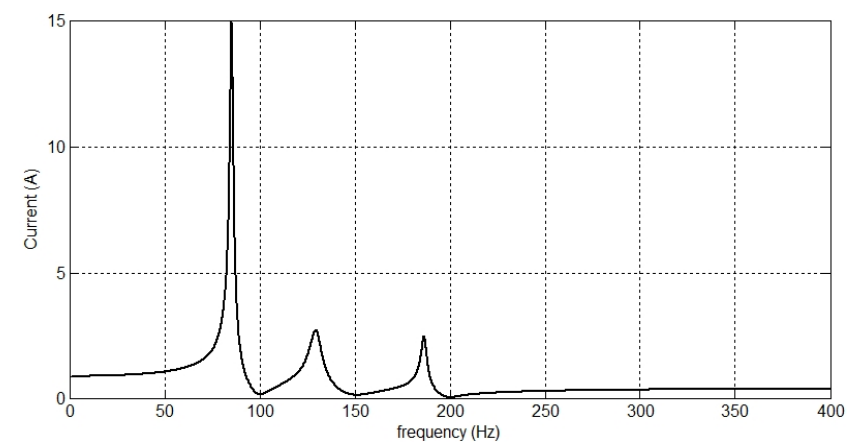

Fig. 16. Harmonic emission of the SIDEMIR $34.5 \mathrm{kV}$ dirty busbar system in case of using series reactor on grid side.

As it is seen in Fig. 16 series reactor application causes $4^{\text {th }}$ Harmonic value to reduce while it causes $2^{\text {th }}$ Harmonic created by the SVC system to rise. Therefore, series reactor 
application does not improve power quality problems of the existing system and affects production performance negatively.

\section{Increasing the Installed Power of the Compensation} System or Replacing the Compensation System with a Static Var Compensation that May Work Faster

The existing Static Var Compensation can be said to be efficient in reducing reactive power but it is clear that using Static Var Compensation causes even harmonics on the network. For this reason, Static Var Compensation is the most important factor increasing flicker effect and it is not efficient to use this type of compensation systems on arc furnaces. Instead of the existing compensation system fast working Thyristor Controlled Reactor (TCR) or Static Compensator (STATCOM) etc. systems can be used.

\section{CONCLUSIONS}

As a result of the experimental studies on the single furnace SIDEMIR EAF-60 system and EMTP simulation analysis the below results have been described in order to improve the power quality of the existing system and make planning for new EAF plants;

1. Power quality problems are mostly seen at boring processes on EAFs. High current values, occurring at boring processes, cause current and voltage harmonics to be high as well. Highest interharmonic values occur at boring and melting phases.

2. Static Var Compensator (SVC) systems are enough for reactive power compensation in EAF plants. But using SVC systems in EAFs especially causes $2^{\text {nd }}$ and $4^{\text {th }}$ Harmonic currents to increase and flicker effect is inevitable. So the existing SVC system should be replaced with new compensation technologies such as a fast working Thyristor Controlled Reactor (TCR) or a Static Compensator (STATCOM) system. This negative effect should also be considered for new plants that are being planned to be built in Turkey.

3. Even if the ratio of the short circuit power at the common connection point to the short circuit power of the EAF (SCMVA min $\left._{\text {mVA }} / \mathrm{MVAF}_{\mathrm{EA}}\right)$ is more than 80 flicker effect can be observed in case of using SVC compensation system. SVC system should not be used in plants considered to be newly planned in Turkey or in case of using SVC system the $\mathrm{SCMVA}_{\min } / \mathrm{MVA}_{\mathrm{EAF}}$ ratio should be chosen above 120 . If these conditions cannot be provided the short circuit power of the network at the common connection point of the EAF system should be increased.

4. In order to reduce flicker effect, electric arc current can be reduced and in this method series reactors are commonly used. When series reactor is used the $4^{\text {th }}$ harmonic values, that caused by SVC system, reduce while the $2^{\text {th }}$ Harmonic values increase. For this reason, in such type of systems, series reactor usage should be realized after analysing harmonic effects by advanced simulation programs. The limitation of the arc current also causes production performance to fall down.

5. The characteristics of the filters to be used for reducing even harmonics caused by SVC systems on EAFs should be observed well with the help of advanced simulation programs like EMTP. Because changing filter characteristics can cause interharmonics to rise up between $50 \mathrm{~Hz}-100 \mathrm{~Hz}$ and $100 \mathrm{~Hz}-150 \mathrm{~Hz}$.

\section{ACKNOWLEDGEMENT}

The authors are indebted to reviewers for their constructive suggestions which significantly helped in improve the quality of this paper and SIDEMIR and TEIAS personnel.

\section{REFERENCES}

[1] TR. Mediterranean Development Agency, "Iron and Steel Sector Report for Turkey", 2014.

[2] O. Solar, et al., "Electrical power quality of iron and steel industry in Turkey", New Orleans, LA, USA, IEEE Conf. Industry Applications, 2007. [Online]. Available: http://dx.doi.org/10.1109/07IAS.2007.67

[3] K. S. R. Rao, M. N. Karsiti, "Optimal design of a furnace transformer by intelligent evolutionary methods", Electrical Power and Energy Systems, vol. 43, no. 1, pp. 1056-1062, 2012. [Online]. Available: https://doi.org/10.1016/j.ijepes.2012.06.019

[4] A. N. Marakov, V. V. Rybakova, M. K. Galicheva, "Electromagnetism and the arc efficiency of electric arc steel melting furnace", Journal of Electromagnetic Analysis and Application, vol. 6, pp. 184-192, 2014. [Online]. Available: https://doi.org/10.4236/jemaa.2014.67018.

[5] A. A. Mattahedi, S. Amani, "Using oxygen reaction as electricity saving in electric arc furnace steel making", International Journal of ChemTech Research, vol. 1, no. 1, pp. 62-70, 2009.

[6] H. Hang, Z. Mao, "Controller design for electrode regulating system of electric arc furnace", $27^{\text {th }}$ Control and Decision Conf. (CCDC), Qingdao, China, 2015. [Online]. Available: https://doi.org/ 10.1109/CCDC.2015.7162040

[7] M. Moghodasian, E. Alenasser, "Modelling and artificial intelligencebased control of electrode system for an electric arc furnace", $J$. Electromagnetic Analysis \& Applications, vol. 3, pp. 47-55, 2011. [Online]. Available: https://doi.org/10.4236/jemaa.2011.32009

[8] R. Hooshmand, M. Banejad, M. T. Estefani, "A new time domain model for electric arc furnace", Journal of Electrical Engineering, vol. 59, no. 4, pp. 195-202, 2008.

[9] A. A. Gomez, J. J. M. Durango ve, A. E. Mejia, "Electric arc furnace modeling for power quality analysis", in Proc. of the IEEE ANDESCON Conf., Bogota, 2010, pp. 1-6. [Online]. Available: https://doi.org/10.1109/ANDESCON.2010.5629655

[10] A. Memmedov, "Effect of arc furnaces working in groups on grid voltage", S. Electric, vol. 215, pp. 142-145, 2007.

[11] M. Seker, A. Memmedov, "Inversigation of voltage quality in electric arc furnace with matlab/simulink", International Journal of Engineering and Technological Research (IJETR), vol. 2, no. 11, 2014.

[12] P. Chittora, A. Singh, M. Singh, "Modelling and analysis of power quality problems in electric arc furnace", Annual IEEE India Conference (INDICON), New Delhi, India, 2015, pp. 1-6. [Online]. Available: https://doi.org/10.1109/INDICON.2015.7443638

[13] D. C. Bhonsle, R. B. Kelkar, "Analyzing power quality issue in electric arc furnace by modelling", Energy, vol. 115, pp. 830-839, 2016. [Online]. Available: https://doi.org/10.1016/j.energy. 2016.09.043

[14] S. Golestani, H. Samet, "Generalised cassie-mary electric arc furnace models", IET Generation, Transmission \& Disturbution, vol. 10, no. 13, pp. 3364-3373, 2016. [Online]. Available: https://doi.org/ 10.1049/iet-gtd.2016.0405

[15] D. Gajic, I. S. Gajic, I. Savic, O. Georgieva, S. D. Gennano, "Modelling of electrical energy consumption in an electric arc furnace using artifical neural network", Energy, vol. 108, pp. 132 139, 2016. [Online]. Available: https://doi.org/10.1016/ j.energy.2015.07.068

[16] P. E. Issouribehere, F. Issouribehere, G. A. Berbera, "Power quality and operating characteristics of electric arc furnace", in Proc. IEEE Power Eng. Soc. Genarel Meeting, 2005, pp. 784-791.

[17] P. E. Issouribehere, J. C. Barbero, G. A. Berbera, F. Issouribehere, "Compability between disturbance emission and argentinian power quality regulations in iron and steel industry", in Proc. IEEE/PES, Transmission \& Distribution Conf. and Exposition (TDC 2006), 
Caracas, Venezuela, pp. 1-6. [Online]. Available: https://doi.org/ 10.1109/TDCLA.2006.311427

[18] J. G. Mayordomo, E. Prieto, A. Hernandez, L. F. Beites, "Arc furnace characterization from an off-line analysis of measurement", in Proc IEEE 9th Int. Conf., Harmonics Quality Power, pp. 1073-1078, Orlando, FL, 2000. [Online]. Available: https://doi.org/ 10.1109/ICHQP.2000.896877

[19] S. I. Deacanu, N. Nopa, A. I. Toma, M. Topor, "Modelling and experimental analysis for modernization of 100 -t EAF", IEEE Trans. Industral Applications., vol. 46, no. 6, pp. 2259-2266, 2010. [Online]. Available: https://doi.org/10.1109/TIA.2010.2072977

[20] M. P. Donsion, J. A. Guemes, F. Oliviera, "Influence of a SVC on AC arc furnaces harmonics, flicker and unbalance measurement and analysis", 15th IEEE Mediterranean Electrotechnical Conf. (MELECON 2010), Valletta, Malta, 2010. [Online]. Available: https://doi.org/10.1109/MELCON.2010.5476032

[21] B. Boulet, J. Wikston, L. Kadar, "The effect of measuring system accuracy on power quality measurements in electrical arc furnace", IEEE Industry Applications Society Annual Meeting, New Orleans, Louisiana, 1997. [Online]. Available: https://doi.org 10.1109/IAS.1997.626365

[22] E. Ozdemirci, et al., "Mobile monitoring system to take PQ snapshots of Turkish electricity transmission system", in Proc. IEEE Instrumentation and Measurement Technology Conf. (IMTC 2007), Warsaw, Poland, 2007, pp. 1-6. [Online]. Available: https://doi.org/ 10.1109/IMTC.2007.379204

[23] T. Demirci, A. Kalaycioglu, B. Boyrazoglu, O. Solar, S. Pakhuylu, M. Dagh, T. Kara, H. S. Aksuyek, C. Topcu, B. Polat, S. Bilgen, S. Umut, I. Cadirci, M. Ermis, "National PQ monitoring network for Turkish electricity transmission system", in Proc. IEEE Instrumentation and Measurement Technology Conf. (IMTC 2007), Warsaw, Poland, 2007, pp. 1-6. [Online]. Available: https://doi.org/10.1109/IMTC.2007.379150

[24] Testing and Measurement Techniques - Power Quality Measurement Methods, IEC 61000-4-30, 2003

[25] H. Nagiraghdam, M. Nagirandahm, M. Mohammedi, "Total harmonic distortion and power loss reduction in DPF mode operation of harmonic passive filters under presence of nonlinear loads in electrical power system", International Journal of Information and Comunication Technology Research, vol. 4, no. 6, 2014.

[26] J. A. Pamilio, S. M. Deckman, "Flicker produced by harmonics modulation", IEEE Trans. Power Del., vol. 18, no. 2, p. 387-392, 2003. [Online]. Available: https://doi.org/10.1109/TPWRD 2002.807455

[27] A. Testa, D. Gallo, R. Langella, "On the processing of harmonics and interharmonics: using hanning window in standart frame", IEEE Trans. Power Delivery, vol. 19, no. 1, pp. 28-34, 2004. [Online]. Available: https://doi.org/10.1109/TPWRD.2003.820437

[28] J. T. E. Miller, Reactive power control in electric system. WilleyInterscience Publication

[29] IEC 61000-4-15 Electromagnetic Compatibility (EMC)- Part 4: Testing and Measurement Techniques- Section 15: Flickermeter Functional and Design Specification, 2003

[30] Turkish Electricity Transmission System Supply Reliability and Quality Regulation, Acceptable Current Harmonic Limits in Electricity Transmission System Supply Reliability and Quality Regulation.

[31] B. Bhargava, "Arc furnace flicker measurement and control", IEEE Trans. On Power Delivery, vol. 8, no. 1, pp. 400-410, 1993. [Online]. Available: https://doi.org/1010.1109/61.180362

[32] S. R. Mendis, M. T. Bishop, J. F. Whtte, "Investigation of voltage flicker in electric arc power system", IEEE Industry Application Magazine, vol. 2, no. 1, pp. 28-34, 1996. [Online]. Available: https://doi.org/10.1109/2943.476595

[33] M. Seker, A. Memmedov, R. Huseyinov, "The modelling of electric arc furnace load with Matlab/SIMULINK", 23 th Signal Processing and Communications Applications Conf. (SIU 2015), Malatya, Turkey, 2015. [Online]. Available: https://doi.org/10.1109/ SIU.2015.7130390

[34] M. Seker, A. Memmedov, R. Huseyinov, "The modelling of three phases electric arc furnace system using Matlab/SIMULINK and examining the harmonic effects with FFT analysis", Int. Artificial Intelligence and Data Processing Symposium (IDAP 2016), Malatya, Turkey, 2016. 